\title{
Avaliação da atividade antioxidante dos compostos fenólicos naturalmente presentes em subprodutos do pseudofruto de caju (Anacardium occidentale L.) Evaluation of the Antioxidant Activity of Phenolic Compounds Naturally Contained in By-products of the Cashew Apple (Anacardium occidentale L.)
}

\author{
Priscila Regina Bolelli BROINIZI ${ }^{1}$, Elma Regina Silva de ANDRADE-WARTHA ${ }^{1}$, Ana Mara de Oliveira e SILVA ${ }^{1}$, \\ Aléxis Jesús Vidal NOVOA ${ }^{3}$, Rosângela Pavan TORRES ${ }^{1}$, Henriette Monteiro Cordeiro AZEREDO ${ }^{2}$, \\ Ricardo Elesbão ALVES², Jorge MANCINI-FILHO ${ }^{1 *}$
}

\begin{abstract}
Resumo
O presente trabalho teve como proposta avaliar a capacidade antioxidante do bagaço e do extrato bruto concentrado (EBC) do pedúnculo de caju, tendo em vista o seu aproveitamento. O potencial antioxidante dos extratos aquoso (EAq) e alcoólico (EAlc) e das frações de ácidos fenólicos livres (AFL) e esterificadas (solúvel AFS e insolúvel AFI) desses subprodutos do pedúnculo de caju clone CCP-76 foi avaliado em sistema $\beta$-caroteno/ácido linoléico, pelo teste de varredura de radical livre [2,2 difenil-1-pricril-hidrazil (DPPH•)] e de Rancimat. Além do mais, o conteúdo de fenólicos totais e o perfil de ácidos fenólicos foram determinados usando-se o reagente de Folin-Ciocateau e por cromatografia gasosa, respectivamente. O EAq e a fração AFL dos subprodutos apresentaram o maior conteúdo de fenólicos. As frações de ácidos fenólicos exibiram expressiva atividade antioxidante, superior aos extratos estudados nos sistemas $\beta$-caroteno e DPPH. Entretanto no teste Rancimat, os extratos apresentaram maior proteção à oxidação em relação às frações e ao BHT. Nas frações foram identificados os ácidos gálico, ferúlico, caféico, protocatecuico, quínico, cinâmico, gentíssico, p-cumárico e salicílico, os quais lhes conferem o potencial antioxidante. Estes resultados caracterizaram in vitro o potencial antioxidante do bagaço e do EBC do pedúnculo de caju clone CCP-76.
\end{abstract}

Palavras-chave: pseudofruto de caju; ácidos fenólicos; atividade antioxidante; sistema modelo $\beta$-caroteno/ácido linoléico; DPPH•; Rancimat.

\begin{abstract}
This study aimed to determine the antioxidant capacity of cashew apple pulp and raw concentrated extract. The antioxidant potential of aqueous (EAq) and alcoholic (EAlc) extracts and of free phenolic acids (FPA) and esterified (soluble - SPA and insoluble - IPA) fractions of the by-products of the cashew apple clone CCP-76 were evaluated in a $\beta$-carotene-linoleate system by the free radical [2,2-diphenyl-1-picrylhydrazyl $(\mathrm{DPPH} \bullet)]$ scavenging assay and the Rancimat test. In addition, the total phenolic content and phenolic acid profile were determined using Folin-Ciocateau reagent and gas chromatography, respectively. The EAq and the FPA fraction of the by-products showed the highest phenolic content. The phenolic acid fractions generally displayed stronger antioxidant activity than the extracts tested with the $\beta$-carotene-linoleate and DPPH systems. However, in the Rancimat test, the extracts showed higher antioxidant activity than the fractions and BHT. Nine phenolic acids (gallic, ferulic, caffeic, protocatechuic, quinic, cinnamic, gentisic, p-coumaric and salicylic acids), which give the fractions their antioxidant potential, were identified and quantified (both free and esterified forms). These results characterized the in vitro antioxidant capacity of the pulp and raw concentrated extract of the cashew apple clone CCP-76.

Keywords: cashew apple; phenolic acids; antioxidant activity; $\beta$-carotene-linoleate system; DPPH•; Rancimat assay.
\end{abstract}

\section{Introdução}

Pesquisas envolvendo compostos antioxidantes oriundos de fontes naturais têm sido desenvolvidas em diferentes centros de estudos devido a sua importância na prevenção do desencadeamento das reações oxidativas, tanto nos alimentos como no organismo animal. Os antioxidantes podem agir retardando ou prevenindo a oxidação do substrato envolvido nos processos oxidativos impedindo a formação de radicais livres ${ }^{9}$.

No século passado, a partir dos anos 80, deu-se o início às pesquisas com antioxidantes naturais visando à substituição total ou parcial dos antioxidantes sintéticos, aos quais

\footnotetext{
Recebido para publicação em 3/5/2007

Aceito para publicação em 30/7/2007 (002475)

${ }^{1}$ Departamento de Alimentos e Nutrição Experimental

Faculdade de Ciências Farmacêuticas, Universidade de São Paulo - USP,

São Paulo - SP, Brasil,

E-mail: jmancini@usp.br

Centro Nacional de Pesquisa de Agroindústria Tropical

Empresa Brasileira de Pesquisa Agropecuária - EMBRAPA,

Fortaleza-CE, Brasil

${ }_{3}^{3}$ Departamento de Bioquímica, Facultad de Biologia, Universidad de la Habana,

Havana, Cuba

*A quem a correspondência deve ser enviada
}

se atribuem efeitos deletérios ao organismo animal quando utilizados em doses elevadas ${ }^{7}$. Além dos possíveis riscos que o uso irregular e/ou indiscriminado dos antioxidantes sintéticos pode acarretar ao homem, soma-se a rejeição generalizada dos aditivos alimentares sintéticos. Ênfase tem sido dada à identificação e purificação de novos compostos com atividade antioxidante, oriundos de fontes naturais, que possam agir sozinhos ou sinergicamente com outros aditivos, como uma forma de prevenir a deterioração oxidativa de alimentos e restringir a utilização dos antioxidantes sintéticos ${ }^{24}$.

Frutas e outros vegetais contêm substâncias antioxidantes distintas, cujas atividades têm sido bem comprovadas nos últimos anos. A presença de compostos fenólicos, tais como flavonóides, ácidos fenólicos, antiocianinas, além dos já conhecidos; vitaminas $\mathrm{C}$, E e carotenóides contribuem para os efeitos benéficos destes alimentos ${ }^{1,25}$. Somando-se a isto, estudos têm demonstrado que polifenóis naturais possuem efeitos significativos na redução do câncer, e evidências epidemiológicas demonstram correlação inversa entre doenças cardiovasculares e consumo de alimentos fonte de substâncias fenólicas, possivelmente por suas propriedades antioxidantes ${ }^{12,22}$. 
No grande grupo dos compostos fenólicos, os flavonóides e os ácidos fenólicos são os que mais se destacam e, são considerados os antioxidantes fenólicos mais comuns de fontes naturais. Estas substâncias apresentam-se amplamente distribuídas no reino vegetal; sendo, desta maneira, encontradas em todas as frutas e outros vegetais ${ }^{12}$.

O caju (Anacardium occidentale L.) é um fruto típico do nordeste brasileiro e cada vez mais o seu cultivo adquire maior importância socioeconômica ${ }^{4}$. Do total produzido anualmente na região Nordeste, $15 \%$ é aproveitado para a fabricação do suco. O restante é destinado à produção da castanha de caju. Nos dois casos, o bagaço é descartado. Dessa forma, pesquisas na Empresa Brasileira de Pesquisa Agropecuária (EMBRAPA) estão sendo realizadas no sentido de desenvolver formas de utilização desse bagaço como, por exemplo, farinha para formulação de pães e biscoitos e na composição de ração animal. Assim, pode-se amenizar o desperdício e aproveitar as sobras nutritivas. O presente estudo teve como objetivo investigar os constituintes fenólicos, em particular os ácidos fenólicos, em subprodutos (bagaço e extrato bruto concentrado) do pedúnculo de caju e avaliar sua atividade antioxidante por meio da capacidade de seqüestro do radical DPPH e pela inibição da oxidação lipídica em sistema modelo $\beta$-caroteno e em teste de Rancimat.

\section{Material e métodos}

\subsection{Material}

As amostras de pedúnculo de caju CCP-76 foram provenientes da Estação Experimental de Pacajus/CE - EMBRAPA, as quais foram submetidas a um tratamento especial, conforme protocolo elaborado pela EMBRAPA (Figura 1), e produzidos o bagaço e o extrato bruto concentrado (EBC) utilizados neste estudo.

Todos os reagentes e solventes utilizados foram de grau analítico. Os padrões de ácido salicílico, trans-cinâmico, p-hidroxibenzóico, vanílico, gentíssico, protocatecuico, quínico, o-cumárico, p-cumárico, gálico, ferúlico, caféico, sináptico, clorogênico, (ácido 5-O-cafeoilquínico), ácido linoléico, hidroxitolueno de butila (BHT), $\beta$-caroteno, DPPH • (2,2-difenil-1 -picrilhidrazila), monopalmitato de polioxietilenosorbitana (Tween 40) e éster metila de ácido heptadecanóico foram obtidos da Sigma Chemical Co. (St. Louis, EUA). O reativo de Folin Ciocalteau, proveniente da Merck (Darmstadt, Alemanha).

\subsection{Métodos}

\section{Preparo dos extratos alcoólico e aquoso}

Os compostos fenólicos presentes tanto no bagaço quanto no EBC foram extraídos sequencialmente por solventes de diferentes polaridades segundo método descrito por KRYGIER et al. ${ }^{13}$ e modificado por MOREIRA e MANCINI-FILHO ${ }^{18}$. Foi feita extração com éter etílico na proporção de 1:5 ( $\mathrm{g}$ da amostra: solvente) durante 1 hora em agitador magnético (modelo RO15 power, IKA ${ }^{\circledR}$, Staufen, Alemanha) à temperatura ambiente. A solução foi filtrada a vácuo em funil de Büchner e o resíduo foi

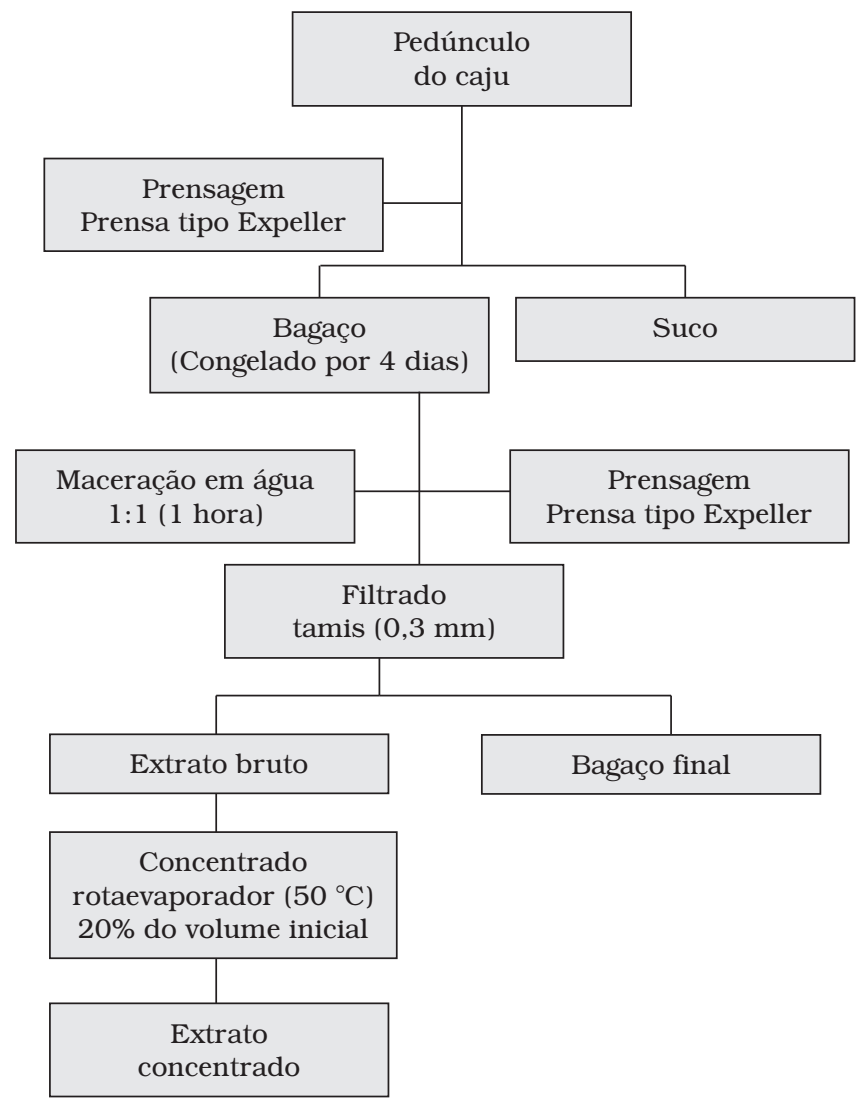

Figura 1. Etapas do processamento para obtenção do bagaço e extrato bruto concentrado (EBC) do pedúnculo de caju.

recuperado a cada extração e usado para obtenção dos extratos subseqüentes, usando como solventes: álcool etílico (extrato alcoólico - EAlc) e água destilada (extrato aquoso - EAq), na mesma proporção inicial e seguindo o mesmo procedimento.

\section{Determinação do conteúdo de fenólicos totais}

O conteúdo total de fenólicos foi medido em triplicata para cada extrato conforme o método de SWAIN e HILLS ${ }^{26}$ usando o reagente Folin-Ciocalteau e padrão de ácido gálico. Os resultados foram expressos em mg de equivalentes de ácido gálico/g de amostra.

\section{Extração, hidrólise e identificação e} quantificação dos ácidos fenólicos

Os ácidos fenólicos livres e esterificados foram identificados por cromatografia a gás (CG) empregando a metodologia descrita por DABROWSKI e SOSULSKI ${ }^{5}$, com modificações realizadas por MOREIRA e MANCINI-FILHO ${ }^{18}$. Um grama de amostra liofilizada foi extraído 6 vezes em Ultra-Turrax (modelo DI 25 basic, IKA ${ }^{\circledR}$, Staufen, Alemanha) com 20 mL de tetrahidrofurano (THF) à temperatura ambiente. As frações obtidas foram combinadas e evaporadas em evaporador rotativo (B525, Micronal, São Paulo, Brasil) sob vácuo, a $30^{\circ} \mathrm{C}$, o concentrado foi ressuspenso em $5 \mathrm{~mL}$ de metanol. Esta fração foi analisada para os ácidos fenólicos livres (AFL). O resíduo restante foi novamente extraído 6 vezes em Ultra-Turrax com solução de metanol:acetona: água ( $1: 1: 1)$ à temperatura ambiente. As 
frações combinadas foram evaporadas em evaporador rotativo sob vácuo a $40{ }^{\circ} \mathrm{C}$ até a fase aquosa. Posteriormente, a suspensão aquosa e o resíduo foram hidrolisados com $\mathrm{NaOH} 4 \mathrm{~N}$ (mesmo volume e $20 \mathrm{~mL}$, respectivamente) por 4 horas sob fluxo de nitrogênio e à temperatura ambiente. Os sobrenadantes foram acidificados com $\mathrm{HCl} 6 \mathrm{~N}$ a pH 2 e extraídos 6 vezes com éter etílico: acetato de etila: THF (1:1:1). Estas frações foram combinadas e evaporadas em evaporador rotativo sob vácuo a $40{ }^{\circ} \mathrm{C}$ e, em seguida, ressuspensas em $5 \mathrm{~mL}$ de metanol, as quais foram analisadas para as frações de ácidos fenólicos livres de ésteres solúveis (AFS) e insolúveis (AFI), provenientes do sobrenadante aquoso e do resíduo, respectivamente.

Os ácidos fenólicos liberados das frações obtidas $(0,25 \mathrm{~mL})$ foram transferidos para vials contendo $0,1 \mathrm{~mL}$ de padrão interno (éster metila de ácido heptadecanóico) e o metanol foi evaporado com nitrogênio antes do processo de sililação realizado pela adição de BSA $(0,2 \mathrm{~mL})$. A solução foi incubada a $60{ }^{\circ} \mathrm{C}$ por 30 minutos, obtendo-se as amostras para serem injetadas no cromatógrafo.

\section{Condições cromatográfica e equipamento}

As determinações cromatográficas foram realizadas em cromatógrafo a gás (modelo GC 17 A, Shimadzu, Kyoto, Japão), equipado com detector de ionização de chama. A separação foi feita em coluna capilar de sílica fundida DB5 (30 m x 0,25 mm x 0,25 $\mu \mathrm{m}$ ) com a fase estacionária composta por $5 \%$ de fenil e $95 \%$ de dimetilpolisiloxano ( $\mathrm{J} \& \mathrm{~W}$ Scientific, USA). O gás de arraste foi hélio com vazão de $1 \mathrm{~mL} \cdot \mathrm{min}^{-1}$; modo split (split ratio 1:50), sendo $300{ }^{\circ} \mathrm{C}$ a temperatura da interface, com o seguinte gradiente de temperatura da coluna: $150{ }^{\circ} \mathrm{C}$ ( 3 minutos); $5^{\circ} \mathrm{C} \cdot \mathrm{min}^{-1}$ até $300^{\circ} \mathrm{C}$ ( 3 minutos) e volume de injeção $1 \mu \mathrm{L}$. As áreas dos picos foram calculadas por um integrador modelo GC Wortkstation Class-GC-10 (Shimadzu, Kyoto, Japão). Os ácidos fenólicos foram identificados comparando os tempos de retenção com os dos padrões (quando disponíveis) e baseando-se no padrão interno.

\section{Atividade antioxidante em sistema modelo $\beta$-Caroteno-ácido linoléico}

A capacidade antioxidante dos extratos e das frações foi avaliada em sistema modelo de co-oxidação de substratos: $\beta$-caroteno/ácido linoléico, método desenvolvido por $\mathrm{MARCO}^{15} \mathrm{e}$ modificado por MILLER ${ }^{17}$. Para o preparo do meio emulsionado, adicionou-se $20 \mu \mathrm{L}$ de solução $\beta$-caroteno $\left(20 \mathrm{mg} \cdot \mathrm{mL}^{-1} \mathrm{de}\right.$ clorofórmio), $40 \mu \mathrm{L}$ de ácido linoléico, $400 \mathrm{mg}$ de emulsificador Tween 40 e $1 \mathrm{~mL}$ de clorofórmio. Posteriormente, o clorofórmio foi totalmente evaporado com nitrogênio. Em seguida, adicionou-se $100 \mathrm{~mL}$ de água, previamente saturada com oxigênio num período de 30 minutos, e agitou-se vigorosamente. Este meio apresentou-se límpido com absorbância entre 0,6 e 0,7 em $470 \mathrm{~nm}$. Alíquotas de $5 \mathrm{~mL}$ da emulsão foram transferidas para tubos espectrofotométricos contendo os extratos (EAq e EAlc) ou as frações (AFL, AFS e AFI) em diferentes concentrações. O BHT foi utilizado como padrão-referência. Os valores da densidade ótica foram obtidos no período de 120 minutos a intervalos de 15 minutos, enquanto as amostras eram mantidas em banho-maria a $50{ }^{\circ} \mathrm{C}$, em espectrofotômetro (modelo
SPECTRONIC $^{\circledR} 20$, GENESYS $^{\mathrm{TM}}$, Rochester, USA). Considerouse como oxidação total (100\%) os tubos contendo apenas o substrato sem o antioxidante e os cálculos foram obtidos por meio de correlação a partir desse valor.

A eficiência do antioxidante foi também expressa a partir dos fatores cinéticos F1 e F2, de acordo com YANISHILIEVA e MARINOVA $^{27}$, calculados por meio das curvas cinéticas de oxidação. Na parte inicial da curva (período entre 15 e 45 minutos de incubação) é mensurada a eficiência do antioxidante em bloquear a reação em cadeia $(\mathrm{F} 1)$ por meio de interação com os radicais peróxidos (Equação 1):

$\mathrm{F} 1=\operatorname{tg} \operatorname{amostra}_{(1545)} / \operatorname{tg}$ controle ${ }_{(1545)}$

No intervalo final da curva (período entre 75 e 105 minutos), infere-se a possibilidade do antioxidante participar de outras reações durante o processo oxidativo, como por exemplo, decomposição dos hidroperóxidos com oxigênio, produzindo espécies radicalares que aceleram a oxidação no sistema (F2). Estas medições foram utilizadas para estabelecer uma relação entre as tangentes das curvas cinéticas das amostras e do controle, a qual expressa a eficiência do antioxidante (Equação 2):

$\mathrm{F} 2=\operatorname{tg} \operatorname{amostra}_{(75105)} / \operatorname{tg}$ controle $\left.{ }_{(75} 105\right)$

\section{Atividade antioxidante em sistema de varredura de radicais livres $(\mathrm{DPPH} \bullet)$}

A atividade antioxidante dos extratos e das frações, tanto do bagaço liofilizado quanto do EBC, foi também avaliada pelo ensaio DPPH • segundo BLOIS ${ }^{2}$ e BRAND-WILLIANS et al. ${ }^{3}$, que tem por base a redução do radical DPPH $\bullet$. Ao fixar um $\mathrm{H} \bullet$, removido do antioxidante em estudo, observa-se uma diminuição da absorbância, o que permite calcular, após o estabelecimento do equilíbrio da reação, a quantidade de antioxidante gasta para reduzir $50 \%$ o radical $\mathrm{DPPH} \bullet$. Uma alíquota de $0,5 \mathrm{~mL}$ de amostra, contendo diferentes concentrações de extratos ou frações, foi adicionada a 1,5 mL de solução metanólica de $\mathrm{DPPH} \bullet 6 \times 10^{-5}$ mol. $\mathrm{L}^{-1}$. Todas as determinações foram acompanhadas de um controle sem as amostras antioxidantes. A redução do radical DPPH • foi medida a $515 \mathrm{~nm}$ em espectrofotômetro (SPECTRONIC ${ }^{\circledR} 20$ GENESYS $^{\mathrm{TM}}$, Rochester, USA) logo após 30 minutos de repouso. O decréscimo nos valores de densidade ótica das amostras foi correlacionado aos do controle e estabelecida a percentagem de descoloração do radical DPPH •, isto é, o seqüestro de radicais livres, expressa pela Equação 3:

$$
\% \text { de proteção }=\left(\mathrm{Abs}_{\text {controle }}-\mathrm{Abs}_{\text {amostra }}\right) / \mathrm{Abs}_{\text {controle }}
$$

\section{Atividade antioxidante em modelo lipídico (Rancimat)}

O princípio da determinação da condutividade no teste Rancimat se baseia na resistência da medição da solução dos ácidos voláteis recuperados ${ }^{16}$.

A capacidade antioxidante dos extratos e das frações do bagaço e do EBC do pedúnculo de caju sobre o óleo vegetal 
foi determinada pela medição do tempo de indução para oxidação do óleo de soja comercial sem antioxidante (fornecido pela Cargill Agrícola S.A.) através do analisador Rancimat ${ }^{\circledR}$ (modelo 743, Metrohm Ltd., Herisau, Suíça) com o software PC 743 Rancimat 1.0. Amostras de $5 \mathrm{~g}$ do óleo contendo EAq e EAlc e/ou frações de ácidos fenólicos do bagaço e do EBC nas concentrações de 100 ppm foram submetidas à oxidação a $110^{\circ} \mathrm{C}$ (fluxo de oxigênio $20 \mathrm{~L} / \mathrm{h}$ ). Todos foram comparados ao BHT nas mesmas concentrações. Os períodos de indução - PI (h) foram registrados automaticamente. Os fatores de proteção (FP) foram calculados de acordo com a fórmula (Equação 4$)^{8}$ :

$\mathrm{FP}=\mathrm{PI}$ amostra $/ \mathrm{PI}_{\text {controle }}$

\section{Análise estatística}

Os resultados foram expressos como média \pm desvio padrão $(n=3)$ para cada extrato e fração. $O$ tratamento estatístico dos dados se deu pela análise de variância (ANOVA) e Teste de Tukey, utilizando o software Prisma 3.0 (GraphPad). O valor de $\mathrm{p}<0,05$ foi considerado estatisticamente significativo.

\section{Resultados e discussão}

\subsection{Conteúdo de fenólicos totais}

Os teores de fenólicos totais para o EAq foram de 2,8 e 10,4 mg de ácido gálico/g de bagaço e de EBC, respectivamente. Enquanto que para o EAlc, estes conteúdos foram de 2,3 e 0,3 mg de ácido gálico/g também de bagaço e de EBC, respectivamente. Estes valores foram significativamente diferentes $(\mathrm{p}<0,05)$ entre si. Tanto o bagaço quanto o EBC apresentaram conteúdo de compostos fenólicos elevados. Analisando polpa de várias frutas, HASSIMOTTO et al. ${ }^{10}$ quantificaram um teor de 2,34 $\mathrm{mg}$ de catequina/g para a polpa de caju, valor próximo daquele encontrado no bagaço mesmo após o tratamento para a sua obtenção.

\section{2 Ácidos fenólicos}

Os principais ácidos fenólicos nas frações AFL, AFS e AFI do bagaço e do EBC do pedúnculo de caju encontram-se na Tabela 1. Um total de nove ácidos fenólicos foram identificados, dos quais quatro foram derivados hidroxilados de ácido benzóico (gálico, protocatecuico, gentíssico e salicílico) e cinco derivados de ácido cinâmico (caféico, ferúlico, cinâmico, quínico e p-cumárico). Além disso, outros compostos não identificados se apresentaram em todas as frações. Dentre os ácidos fenólicos identificados, o ácido salicílico foi o mais abundante em todas as frações. Nas frações AFL de ambos os subprodutos do pedúnculo, além do ácido salícilico, o p-cumárico encontra-se presente em expressivas concentrações. $\mathrm{O}$ ácido gálico foi o segundo predominante nas frações AFS das amostras analisadas.

\subsection{Atividade antioxidante em sistema modelo $\beta$-caroteno/ácido linoléico}

A atividade antioxidante das frações e dos extratos mensurada em sistema modelo $\beta$-caroteno/ácido linoléico está
Tabela 1. Conteúdo nas frações de ácidos fenólicos livres (AFL) e esterificadas solúvel (AFS) e insolúvel (AFI) de bagaço e EBC de pedúnculo de caju ${ }^{\mathrm{a}}$

\begin{tabular}{lccccccc}
\hline Fração de ácidos fenólicos & \multicolumn{3}{c}{ Bagaço } & & \multicolumn{2}{c}{ EBC } \\
\cline { 2 - 3 } \cline { 6 - 7 } & AFL & AFS & AFI & & AFL & AFS \\
\hline Salicílico & 1270 & 984 & 610 & & 1660 & 741 \\
Cinâmico & - & 0,1 & - & & 19,6 & 0,2 \\
Gentíssico & - & 0,1 & - & & - & 38,3 \\
Protocatecuico & - & 0,2 & - & & - & 0,1 \\
Quínico & - & 0,03 & - & & - & 0,05 \\
p-cumárico & 20 & 0,1 & 0,01 & & 145,2 & 0,1 \\
Gálico & 0,04 & 36 & 0,1 & & 31,4 & 33,6 \\
Ferúlico & 0,02 & 0,05 & 0,03 & & 0,15 & 0,05 \\
Caféico & 0,1 & 0,04 & 0,04 & & 0,05 & 0,05 \\
\hline${ }^{a}$ Os resultados estão expressos como média e mg.g ${ }^{-1}$. & & &
\end{tabular}

representada na Figura 2. O BHT $(0,01 \mathrm{mg})$ exibiu um potencial antioxidante elevado (83,5\%). No entanto, como se pode observar nos resultados, as frações de ácidos fenólicos se mostraram mais efetivas do que o antioxidante sintético e os extratos (Tabelas 2 e 3).

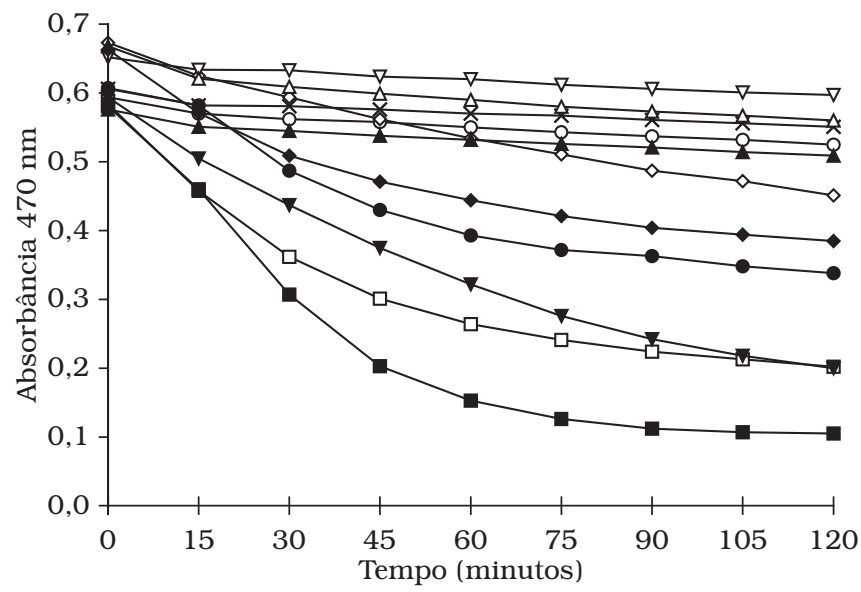

\begin{tabular}{rlr|}
$\rightarrow-$ Controle & $\rightarrow$ BHT & - EAlc Bagaço \\
$\rightarrow-$ EAq Bagaço & - EAq EBC & - AFL Bagaço \\
$-\square-$ EAlc EBC & $\rightarrow$-AFS Bagaço & - - AFL EBC \\
& $\checkmark$ AFI Bagaço & $*$ AFS EBC \\
\hline
\end{tabular}

Figura 2. Atividade antioxidante dos extratos e frações de ácidos fenólicos do bagaço e extrato bruto concentrado $(\mathrm{EBC})$ do pedúnculo de caju em sistema modelo $\beta$-caroteno/ácido linoléico.

Os extratos provenientes do bagaço inibiram a oxidação do $\beta$-caroteno na ordem de $30 \%$ na menor concentração ( $2,5 \mathrm{mg}$ ), sendo esta o limite de eficiência da capacidade antioxidante para o EAq do bagaço (Tabela 2). Vale salientar que o pedúnculo de caju clone $\mathrm{CCP}-76$, submetido a um tratamento especial, manteve a atividade antioxidante em patamares de detecção analítica. Sendo assim, o pedúnculo de caju além de possuir elevado conteúdo de compostos fenólicos totais, ainda demonstra capacidade antioxidante em sistema de co-oxidação $\beta$-caroteno/ácido linoléico.

As frações de ácidos fenólicos (AFL e AFS) apresentaram elevada atividade antioxidante com valores superiores ao 
Tabela 2. Atividade antioxidante dos extratos aquoso (EAq) e alcoólico (EAlc) de bagaço e de EBC de pedúnculo de caju ${ }^{\mathrm{a}}$.

\begin{tabular}{|c|c|c|c|c|c|c|}
\hline \multirow[t]{2}{*}{ Extratos } & \multicolumn{3}{|c|}{ Inibição da oxidação em modelo sistema $\beta$-caroteno (\%) } & \multicolumn{3}{|c|}{ Atividade de varredura do radical DPPH (\%) } \\
\hline & $2,5 \mathrm{mg}$ & $5 \mathrm{mg}$ & $10 \mathrm{mg}$ & $0,125 \mathrm{mg}$ & $0,25 \mathrm{mg}$ & $0,5 \mathrm{mg}$ \\
\hline EAq Bagaço & $33 \pm 3,2^{b}$ & $33 \pm 5,2^{b}$ & $17 \pm 0,4^{b}$ & $54 \pm 4,2^{\mathrm{b}}$ & $90 \pm 0,2^{b}$ & $88 \pm 0,2^{\mathrm{a}}$ \\
\hline EAlc Bagaço & $34 \pm 1,6^{\mathrm{b}}$ & $32 \pm 7,9^{b}$ & $50 \pm 4,2^{c}$ & $57 \pm 1,3^{b}$ & $93 \pm 2,4^{c}$ & $95 \pm 0,3^{b}$ \\
\hline EAq EBC & $5,8 \pm 0,01^{c}$ & $12 \pm 0,1^{c}$ & $17 \pm 0,4^{b}$ & $65 \pm 5,4^{c}$ & $88 \pm 0,6^{b}$ & $90 \pm 0,2^{c}$ \\
\hline EAlc EBC & $7,6 \pm 2,7^{c}$ & $11 \pm 3,3^{c}$ & $27 \pm 6,4^{\mathrm{d}}$ & $36 \pm 3,2^{\mathrm{d}}$ & $65 \pm 1,0^{\mathrm{d}}$ & $93 \pm 0,1^{\mathrm{d}}$ \\
\hline
\end{tabular}

as resultados estão expressos como média \pm desvio padrão $(\mathrm{n}=3$ ); e Médias seguidas da mesma letra na coluna não diferem estatisticamente ( $\mathrm{p}>0,05)$.

Tabela 3. Atividade antioxidante das frações de ácidos fenólicos livre (AFL) e esterificadas solúvel (AFS) e insolúvel (AFI) de bagaço e de EBC de pedúnculo de cajua .

\begin{tabular}{|c|c|c|c|c|c|c|}
\hline \multirow[t]{2}{*}{ Frações } & \multicolumn{3}{|c|}{ Inibição da oxidação em modelo sistema $\beta$-caroteno (\%) } & \multicolumn{3}{|c|}{ Atividade de varredura do radical DPPH (\%) } \\
\hline & $50 \mu \mathrm{g}$ & $100 \mu \mathrm{g}$ & $250 \mu \mathrm{g}$ & $12,5 \mu \mathrm{g}$ & $25 \mu \mathrm{g}$ & $50 \mu \mathrm{g}$ \\
\hline AFL Bagaço & $70 \pm 0,3^{b}$ & $75 \pm 0,6^{b}$ & $80 \pm 0,7^{b}$ & $40 \pm 0,6^{b}$ & $56 \pm 5,7^{b}$ & $77 \pm 0,3^{a}$ \\
\hline AFS Bagaço & $73 \pm 2,0^{\mathrm{b}}$ & $85 \pm 2,3^{c}$ & $90 \pm 1,1^{\mathrm{c}}$ & $94 \pm 0,1^{c}$ & $93 \pm 1,2^{\mathrm{c}}$ & $93 \pm 0,2^{\mathrm{b}}$ \\
\hline AFL EBC & $70 \pm 3,5^{b}$ & $80 \pm 1,7^{\mathrm{bc}}$ & $86 \pm 1,9^{\mathrm{bc}}$ & $42 \pm 0,4^{\mathrm{b}}$ & $58 \pm 0,1^{\mathrm{b}}$ & $66 \pm 0,3^{\mathrm{d}}$ \\
\hline AFS EBC & $71 \pm 1,0^{b}$ & $82 \pm 1,5^{\mathrm{bc}}$ & $89 \pm 0,6^{\mathrm{ec}}$ & $40 \pm 1,3^{b}$ & $58 \pm 0,3^{b}$ & $82 \pm 0,2^{\mathrm{e}}$ \\
\hline
\end{tabular}

${ }^{a}$ Os resultados estão expressos como média \pm desvio padrão $(n=3)$. Médias seguidas da mesma letra na coluna não diferem estatisticamente $(\mathrm{p}>0,05)$.

BHT, o que caracteriza o excelente potencial antioxidante dos ácidos fenólicos isolados nestas frações (Tabela 3), os quais são representados pelos ácidos gálico, p-cumárico, protocatecuico, ferúlico, caféico cinâmico, quínico, gentíssico e salicílico (Tabela 1). Os derivados de ácidos cinâmicos, dentre eles, ácido caféico e protocatecuico, e derivados de ácidos benzóicos, ácido gálico, demonstraram grande potencial antioxidante em ensaios utilizando íons de $\mathrm{Cu}^{2+}$ para a catálise da LDL oxida$\mathrm{da}^{20}$. Somando-se a isto, destaca-se a propriedade do ácido ferúlico como seqüestrante de radicais livres, até mesmo em concentrações muito reduzidas ${ }^{11}$, o que dá subsídio para supor que a elevada atividade antioxidante em todas as frações de ácidos fenólicos dos distintos subprodutos estaria também correlacionada com a presença do ácido ferúlico em todas as frações de ácidos fenólicos, presentes como traço. O ácido gálico também possui um potencial antioxidante bem caracterizado. Em um estudo realizado em ratos com senescência acelerada e suplementados com ácido gálico, verificou-se que, além de restabelecer a atividade das enzimas antioxidantes CAT e GPx, houve redução do nível aumentado de peroxidação lipídica, levando à diminuição significativa da quantidade de substâncias reativas ao ácido tiobarbitúrico no fígado, cérebro e rim $^{14}$. MOREIRA e MANCINI-FILHO ${ }^{19}$ identificaram numa infusão, a partir de uma mistura de especiarias (mostarda, canela e erva-doce) os ácidos fenólico salicílico e caféico. Este chá à base de ervas apresentou um percentual de inibição da oxidação significativo em torno de $90 \%$. Conquanto, destaca-se que a elevada capacidade antioxidante das frações não se deve apenas a um ácido fenólico, mas possivelmente a associação deles, a qual conduz a uma potencialização desta atividade.

Complementando a avaliação da ação antioxidante in vitro dos extratos e frações, foi verificada a sua eficiência pela análise cinética das curvas traçadas pela descoloração do $\beta$-caroteno versus tempo de incubação (Figura 2) estabelecido pelo cálculo dos fatores F1 (estabilização) e F2 (proteção). De acordo com os resultados dos extratos (Tabela 4) e das frações (Tabela 5), os valores de F1 indicam uma grande capacidade de bloqueio
Tabela 4. Fatores cinéticos caracterizando a inibição da oxidação do sistema $\beta$-caroteno/ácido linoléico pelos extratos aquoso e alcoólico do bagaço e de EBC do pedúnculo de cajua .

\begin{tabular}{|c|c|c|c|c|c|c|}
\hline & \multicolumn{6}{|c|}{ Fatores cinéticos } \\
\hline & \multicolumn{2}{|c|}{$2,5 \mathrm{mg}$} & \multicolumn{2}{|c|}{$5 \mathrm{mg}$} & \multicolumn{2}{|c|}{$10 \mathrm{mg}$} \\
\hline & $\mathrm{F} 1$ & $\mathrm{~F} 2$ & $\mathrm{~F} 1$ & $\mathrm{~F} 2$ & $\mathrm{~F} 1$ & $\mathrm{~F} 2$ \\
\hline EAq Bagaço & 0,4 & 3,0 & 0,6 & 2,5 & 0,5 & 3,0 \\
\hline EAlc Bagaço & 0,4 & 2,9 & 0,4 & 2,5 & 0,3 & 1,5 \\
\hline
\end{tabular}

${ }^{\mathrm{a}} \mathrm{F} 1<1$, indica que os antioxidantes são capazes de inibir os radicais livres durante o período de indução; F2 < 1, indica que os antioxidantes podem regenerar o radical antioxidante formado: e F1 e F1 $\geq 1$ indicam atividade pró-oxidante.

Tabela 5. Fatores cinéticos caracterizando a inibição da oxidação do sistema $\beta$-caroteno/ácido linoléico pelas frações de ácidos fenólicos do bagaço e de EBC do pedúnculo de cajua .

\begin{tabular}{|c|c|c|c|c|c|c|}
\hline & \multicolumn{6}{|c|}{ Fatores cinéticos } \\
\hline & \multicolumn{2}{|c|}{$50 \mu \mathrm{g}$} & \multicolumn{2}{|c|}{$100 \mu \mathrm{g}$} & \multicolumn{2}{|c|}{$250 \mu \mathrm{g}$} \\
\hline & $\mathrm{F} 1$ & $\mathrm{~F} 2$ & $\mathrm{~F} 1$ & $\mathrm{~F} 2$ & $\mathrm{~F} 1$ & $\mathrm{~F} 2$ \\
\hline $\mathrm{BHT}$ & 0,5 & 3,1 & 0,3 & 2,1 & 0,2 & 3,1 \\
\hline AFL Bagaço & 0,1 & 0,7 & 0,03 & 0,3 & 0,2 & 0,8 \\
\hline AFS Bagaço & 0,04 & 0,5 & 0,01 & 0,3 & 0,01 & 0,1 \\
\hline AFI Bagaço & 0,03 & 5,6 & 0,04 & 2,0 & 0,14 & 1,4 \\
\hline AFL EBC & 0,2 & 4,4 & 0,1 & 1,7 & 0,05 & 1,5 \\
\hline AFS EBC & 0,2 & 1,2 & 0,1 & 0,9 & 0,05 & 0,7 \\
\hline
\end{tabular}

${ }^{\mathrm{a}} \mathrm{F} 1<1$, indica que os antioxidantes são capazes de inibir os radicais livres durante o período de indução; $\mathrm{F} 2<1$, indica que os antioxidantes podem regenerar o radical antioxidante formado; e F1 e F1 1 indicam atividade pró-oxidante.

da formação inicial de radicais livres in vitro. Nesta fase inicial do processo de oxidação, a eficiência das frações foi melhor do que a do BHT em todas as concentrações testadas. Para a fase de propagação, verificada pelos valores de F2, apenas as frações AFL e AFS do bagaço e AFS do EBC demonstraram eficiência antioxidante.

\subsection{Atividade antioxidante em sistema de varredura de radical DPPH•}

A capacidade de seqüestrar o radical DPPH (expressa em percentual de inibição) exibida pelos extratos e frações 
do bagaço e EBC do pedúnculo de caju CCP-76 encontra-se nas Tabelas 2 e 3. Este método se baseia na transferência de elétrons de um composto antioxidante para um radical livre, o DPPH•, que ao se reduzir perde sua coloração púrpura. Desta forma, avalia apenas o poder redutor do antioxidante, que ao doar um elétron se oxida, e por este motivo não detecta substâncias pró-oxidantes ${ }^{6}$. Todos os extratos, diferentemente das frações, apresentaram comportamento distinto daquele observado no sistema $\beta$-caroteno/ácido linoléico, mostrando efetiva atividade de varredura do radical, principalmente na maior concentração (0,5 mg), com percentuais acima de $88 \%$ (Tabela 2). Com base nestes dados, evidencia-se que os compostos bioativos presentes tanto nos extratos como nas frações podem agir como seqüestradores de radicais pela capacidade de atuar como doador de hidrogênio ${ }^{24}$.

\subsection{Fator de proteção medido pela condutividade em Rancimat}

O óleo de soja sem antioxidante (controle) é oxidado após 6,5 horas. Contudo, o tempo necessário para o período de indução da oxidação do óleo foi maior quando os extratos e o aditivo (BHT) foram adicionados. A capacidade antioxidante (expressa como valores de FP) está ilustrada na Figura 3. Os valores de FP dos extratos EAq e EAlc foram mais elevados (1,2 em ambos) quando comparados ao antioxidante sintético BHT $(1,0)(p<0,05)$. A fração AFI foi a que demonstrou menor proteção antioxidante $(0,9)$ no sistema lipídico. As demais frações não diferiram estatisticamente do BHT ( $\mathrm{p}>0,05)$. Frutas tropicais, tais como: manga, mamão, abacate, maracujá, abacaxi, carambola e banana, apresentaram FP acima de 1,1, ou seja, maior do que os antioxidantes sintéticos BHT e BHA (em torno de 1,0$)$ valores próximos dos encontrados neste trabalho ${ }^{21}$. PROESTOS et al. ${ }^{23}$ examinaram os valores de FP para padrões de ácidos fenólicos: ácidos gentíssico, caféico, p-cumárico, vanílico, siríngico, ferúlico, p-hidrobenzóico (adição de 0,02\%) para óleo de girassol e verificaram uma média de variação de 1,2 a 1,5, excetuando-se o ácido gálico cuja média foi de

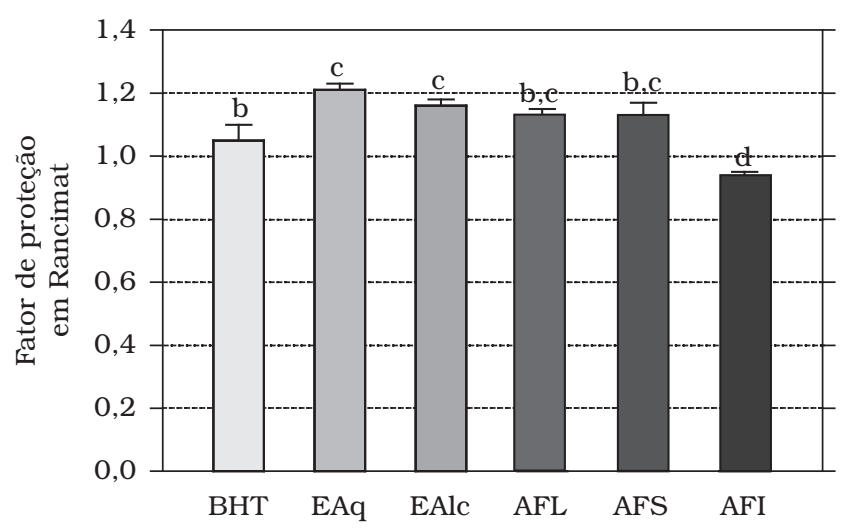

Figura 3. Fator de proteção obtido para óleo de soja refinado sem antioxidante a partir de extratos aquoso (EAq) e alcoólico (EAlc) e de frações de ácidos fenólico livre (AFL) e de esterificados (solúvel - AFS e insolúvel - AFI) comparado a um aditivo alimentício comum (BHT) em meio lipídico por teste de Rancimat a $110^{\circ} \mathrm{C}$.
4,5. Estes valores corroboraram o potencial antioxidante dos extratos metanólicos e de matéria seca de plantas aromáticas da Grécia, ricas nestes compostos fenólicos.

Analisando o potencial antioxidante do EBC e do bagaço do pedúnculo de caju nos três sistemas, verifica-se que a capacidade antioxidante de compostos fenólicos depende de vários fatores: que vão desde o sistema de oxidação, grau de glicolisação à concentração e às variáveis mensuradas, sugerindo que o potencial antioxidante é o resultado da combinação de diferentes compostos existentes nas frutas e outros vegetais. Além dos estudos dos constituintes químicos do pedúnculo do caju, deve-se também considerar pesquisas que abranjam outros parâmetros como: a absorção, o metabolismo, a excreção e o comportamento em modelos experimentais e humanos.

\section{Conclusões}

Pode-se identificar a atividade antioxidante nos extratos e nas frações dos subprodutos do caju (bagaço e EBC) por meio de três diferentes métodos utilizados. As frações AFL e esterificadas (AFS e AFI) do bagaço e do EBC do pedúnculo de caju demonstraram atividade antioxidante superior aos extratos (EAq e EAlc) e ao BHT. Estes resultados abrem a perspectiva de se ter um melhor aproveitamento dos resíduos resultantes do processamento do pedúnculo de caju.

\section{Agradecimentos}

Os autores agradecem à EMBRAPA, ao CNPq e à FAPESP pelo suporte financeiro.

\section{Referências bibliográficas}

1. AJAIKUMAR, K. B. et al. The inhibition of gastric mucosal injury by Punica granatum L. (pomegranate) methanolic extract. J. Ethnopharmacol., Lausanne, v. 96, n. 1/2, p. 171-76, 2005.

2. BLOIS, M. S. Antioxidant Determinations by the Use of a Stable Free Radical. Nature, London, v. 118, p. 1199-1200, 1958.

3. BRAND-WILLIANS, W.; CUVELIER, M. E.; BERSET, C. Use of Free Radical Method Evaluate Antioxidant Activity. Lebensm, Wiss. u. - Technol., London, v. 28, n. 1, p. 25-30, 1995.

4. CARDOSO, J. E. et al. Genetic resistance of dwarf cashew (Anacardium occidentale L.) to anthracnose, black mold, and angular leaf spot. Crop Protection, Guildford, v. 18, n. 1, p. 23-27, 1999.

5. DABROWSKI, K. J.; SOSULSKI, F. W. Quantification of free and hydrolysable phenolic acids in seeds by capillary gas-liquid chromatography. J. Agric. Food. Chem., Washington, v. 32, n. 1, p. 123-27, 1984.

6. DUARTE-ALMEIDA, J. M. et al. Avaliação da atividade antioxidante utilizando sistema $\beta$-caroteno/ácido linoléico e método de seqüestro de radicais DPPH. Ciênc. Tecnol. Aliment. Campinas, v. 26, n. 2. p. 446-52, 2006.

7. DURAN, R. M.; PADILLA, R. B. Actividad antioxidante de los compuestos fenólicos. Grasas y Aceites, Sevilla, v. 44, n. 2 , p. 101-6, 1993.

8. EXARCHOU, V. et al. Antioxidant activities and phenolic composition of extracts from greek oregano, greek sage, and summer savory. J. Agric. Food Chem., Washington, v. 50, n. 19, p. 5294-99, 2002. 
9. HALLIWEL, B. et al. The characterization of antioxidants. Food Chem. Toxicol., Oxford, v. 33, n. 7, p. 601-17, 1995.

10. HASSimotTO, N. M. A.; GENOVESE, I. S.; LAJOLO, F. M. Antioxidant activity of dietary fruits, vegetables, and commercial frozen fruit pulps. J. Agric. Food Chem., Washington, v. 53, n. 8, p. 2928-35, 2005.

11. HSIEH, C. L.; YEN, G. C.; CHEN, H. Y. J. Antioxidant activities of phenolic acids on ultraviolet radiation-induced erythrocyte and low density lipoprotein oxidation. J. Agric. Food Chem., Washington, v. 53, n. 15, p. 6151-55, 2005.

12. KARAKAYA, S. Bioavailability of Phenolic Compounds. Critical Rev. Food Sci. Nutr., Boca Raton, v. 44, n. 6, p. 453-64, 2004.

13. KRYGIER, K.; SOSULSKI, F.; HOGGER, L. Free, sterified, and insoluble-bound phenolic acids. 1. Extraction and purification procedure. J. Agric. Food Chem., Washington, v. 30, n. 2, p. 330-34, 1982.

14. LI, L. et al. Antioxidant activity of garlic acid from rose flowers in senescence accelerated mice. Life Sciences, Oxford, v. 77, n. 2 , p. 230-40, 2005.

15. MARCO, G. J. A rapid method fo evaluation of antioxidants. J. Am. Oil Chem. Soc., Champaign, v. 45, n. 9, p. 594-98, 1968.

16. MÉNDEZ, E. et al. Validation of the Rancimat test for the assessment of the relative stability of fish oils. J. Am. Oil Chem. Soc., Champaign, v. 73, n. 8, p. 1033-37, 1996.

17. MILLER, H. E. Simplified method for evaluation of antioxidants. J. Amer. Oil Chem. Soc., Champaign, v. 48, n. 2, p. 91, 1971.

18. MOREIRA, A. V. B.; MANCINI-FILHO, J. Atividade antioxidante das especiarias mostarda, canela e erva-doce em sistemas aquoso e lipídico. Revista Nutrire, São Paulo, v. 39, p. 31-46, 2003.

19. MOREIRA, A. V. B.; MANCINI-FILHO, J. Influência dos compostos fenólicos de especiarias sobre a lipoperoxidação e o perfil lipídico de tecidos de ratos. Rev. Nutr., Campinas, v. 17, n. 4, p. 41124,2004 .

20. MORTON, L. W. et al. Chemistry and biological effects of dietary phenolic compounds: relevance to cardiovascular disease. Clin. Experim. Pharmacol. Physiol., Oxford, v. 27, n. 3, p. 152-59, 2000.

21. MURCIA, M. A.; JIMÉNEZ, A. M.; MARTÍnEZ-TOME, M. Evaluation of the antioxidant properties of Mediterranean and tropical fruits compared with common food additives. J. Food Prot., Des Moines, v. 64, n. 12, p. 2037-46, 2001.

22. NINFALI, P. et al. Antioxidant capacity of vegetables, spices and dressings relevant to nutrition. Br. J. Nutr., Wallingford, v. 93, n. 2, p. 257-66, 2005.

23. PROESTOS, C. et al. Analysis of flavonoids and phenolic acids in Greek aromatic plants: Investigation of their antioxidant capacity and antimicrobial activity. Food Chem., Barking, v. 95, n. 4, p. 664-71, 2006.

24. Shahidi, F.; AlASAlVAR, C.; LiYANA-PATHIRANA, C. M. Antioxidant Phytochemicals in Hazelnut Kernel (Corylus avellana L.) and Hazelnut Byproducts. J. Agric. Food Chem., Washington, v. 55, n. 4, p. 1212-20, 2007.

25. SILVA, B. M. et al. Quince (Cydonia oblonga Miller) fruit (pulp, peel, and seed) and jam: Antioxidant activity. J. Agric. Food Chem., Washington, v. 52, n. 15, p. 4705-12, 2004.

26. SWAIN, T.; HILLIS, W. E. The phenolic constituents of Prunnus domestica. I - quantitative analysis of phenolic constituents. J. Sci. Food Agric., London, v. 19, n. 1, p. 63-68, 1959.

27. YANISHLIEVA, N. V. I.; MARINOVA, E. M. Effects of antioxidants on the stability of triacylglycerols and methyl esters of fatty acids of sunflower oil. Food Chem., Barking, v. 54, n. 4, p. 377-82, 1995. 